\title{
EFEK SISA JERAMI DAN TITONIA YANG DIKOMPOSKAN TERHADAP PRODUKSI PADI SAWAH
}

\author{
Gusnidar*, Syafrimen Yasin, Mimin Harianti, Tutik Oktaviana \\ Soil Science Departement, Andalas University, Padang, West Sumatera, Indonesia \\ *Email address: gusnidar.a02@gmail.com; mobile: +6281363389265
}

\begin{abstract}
The experiment to obtain residue compost of rice straw (S) and tithonia (T) for reduce commercial fertilizers $(\mathrm{CF})$ input and that effect for rice production. This research was arranged in Completely Randomized Block Design (RBD) with three replications of six treatments. The residue treatments are; A (input Urea $200 \mathrm{~kg} \mathrm{ha}^{-1}(\mathrm{Ru})+\mathrm{SP}-36100 \mathrm{kgha}^{-1}(\mathrm{Rp})+\mathrm{KCl} 75 \mathrm{kgha}^{-1}(\mathrm{Rk})$ ), B $(\mathrm{Ru}+2 \mathrm{Rp}), \mathrm{C}\left(\mathrm{S} 5\right.$ tonsha $\left.^{-1}+\mathrm{R}\right), \mathrm{D}\left(\mathrm{S} 5\right.$ tonsha $^{-1}+\mathrm{Ru}+$ Pstarter $\left.(\mathrm{Ps})\right), \mathrm{E}\left(\mathrm{T}, 2, .5\right.$ tonsha $^{-1}+\mathrm{J}, \quad 2, .5$ tonsha $\left.^{-1}+75 \% \mathrm{Ru}+\mathrm{Ps}\right), \mathrm{F}\left(\mathrm{T}, 2, .5\right.$ tonsha $^{-1}+\mathrm{J}, \quad 2,5$ tonsha $\left.^{-1}+50 \% \mathrm{Ru}+\mathrm{Ps}\right)$. Data of research were statistically analysed. If the F-calculated was significantly different, they would be further analysed using LSD 0.05 . The results showed that residue of T, 2,5 tonha- ${ }^{-1}$ could reduce CF by 50 $\mathrm{kg} \mathrm{Ureaha}^{-1}(25 \% \mathrm{R}), 75 \mathrm{~kg} \mathrm{KCl} \mathrm{ha}^{-1}(100 \% \mathrm{R})$ and $90 \mathrm{~kg} \mathrm{SP}^{-36 \mathrm{ha}^{-1}}(90 \% \mathrm{R})$ with production 6,66 tonsha ${ }^{-1}$ Husk Rice (HC). If it is based on farmer tradition, residue of $\mathrm{T}$ could reduce CF by $50 \mathrm{~kg}$ Ureaha $^{-1}(25 \% \mathrm{R})$, and $190 \mathrm{~kg} \mathrm{SP}-36 \mathrm{ha}^{-1} 0.95$.
\end{abstract}

Key words : compost, residue, rice, straw, tithonia

(C) 2018 Gusnidar Gusnidar, Syafrimen Yasin, Mimien Harianti, Tutik Oktaviana

\section{PENDAHULUAN}

Penggunaan bahan organik (BO) sebagai pupuk alam (PA) mampu mengurangi aplikasi pupuk pabrik $(\mathrm{PP})$ nitrogen $(\mathrm{N})$, fosfor $(\mathrm{P})$, dan potassium $(\mathrm{K})$ karena $\mathrm{BO}$ sebagai bahan yang dapat melepaskan nutrisi berupa hara untuk tanaman. Bahan tersebut dapat melarutkan kadar P berlebihan di lahan sawah intensifikasi (SI). Selama pelapukan BO dilepaskan asamasam organik (AO). Bahan organik lokal yang ada di pinggiran sawah dan berpotensi digunakan berkesinambungan antara lain tumbuhan semak paitan atau titonia (T)) (Gusnidar, 2007).

Dari hasil penelitian Gusnidar (2007) biomas segar $\mathrm{T}$ setara $0,5 \mathrm{~kg}$ kering per meter baris pematang sawah. Untuk satu kali pangkasan (2 bulan) rata-rata kadar haranya adalah $4.3 \% \mathrm{~N} ; 4.3 \% \mathrm{~K} ; 0.4 \% \mathrm{P}$; sehingga menghasilkan $71 \mathrm{~g} \mathrm{~N}$ dan $72 \mathrm{~g} \mathrm{~K}$ serta $7 \mathrm{~g} P$ permeter baris pematang. Selain N, $\mathrm{P}$, dan $\mathrm{K}$, titonia juga mengandung $1,14 \%$ calsium (Ca)), dan 0,8\% magnesium ( $\mathrm{Mg}$ ), ratio $\mathrm{C} / \mathrm{N} 14, \mathrm{C} / \mathrm{P} 154$; kadar lignin $17 \%$; serta selulosa $53 \%$. Titonia sangat mudah tumbuh, bertunas banyak setelah dipangkas terutama pada musim hujan, serta merupakan gulma tahunan yang hidup berkelanjutan dan layak dibudidayakan sebagai sumber BO in situ di lahan persawahan sehingga BO mudah didapatkan. Sisa-sisa panen berupa jerami padi (JP) juga merupakan BO yang sangat potensial di lahan persawahan.

Pengembalian JP pada lahan sawah baik pengaruhnya terhadap sifat biologi, sumbangan hara, dan sifat fisik tanah. Limbah JP jika dikembalikan ke lahan dapat menjadi erupakan sumber hara utama K, dan silikat (Si). Sekitar $80 \% \mathrm{~K}$ yang diserap tanaman, berada dalam JP. Pengembalian JP ke tanah dapat memperlambat pemiskinan $\mathrm{K}$ dan $\mathrm{Si}$ tanah. Salah satu hasil penelitian menyatakan bahwa dengan membenamkan JP 5 tonha $^{-1}$ untuk satu musim, selama 4 musim pada tanah sawah kahat $\mathrm{K}$, dapat menggantikan (subsitusi) pupuk $\mathrm{K}$ buatan, meningkatkan produksi serta kesuburan kimia dan fisika tanah (Liptan, 2000).

Kandungan Si JP rata-rata sebesar 3,16\% (Gusnidar et al 2008). Unsur $\mathrm{Si}$ 
merupakan hara essensial bagi tanaman padi. Berdasarkan hasil penelitian Naim (1982), pemberian $\mathrm{Si}$ dapat meningkatkan pertumbuhan dan produksi padi $\quad\left(17,44\right.$ gpot $^{-}$ 1 tanpa Si menjadi 27,43 gpot $^{-1}$ dengan $\mathrm{Si}$ setara $336 \mathrm{~kg} \mathrm{SiO}_{2} \mathrm{ha}^{-1}$ ), terutama kondisi pemberian air pada kapasitas lapang (KL). Kompos merupakan rabuk alam, dengan bahan asal sarasah, limbah kebun dan tanaman, sampah kota, makanan ternak yang bercampur dengan kotorannya, dan lain-lain yang ditumpuk, agar mengalami pelapukan sehingga dapat digunakan sebagai pupuk. Kualitas kompos sebagai PO akan dipengaruhi oleh bahan asalnya. Umumnya bahan-bahan yang berasal dari tumbuhan seperti JP dan sampah kota sering didapatkan dalam jumlah yang banyak, tetapi tidak banyak dimanfaatkan oleh petani. Bahan ini mempunyai nisbah $\mathrm{C} / \mathrm{N}$ yang terlalu tinggi $(>40)$. Agar bahan tersebut mengandung nisbah $\mathrm{C} / \mathrm{N}$ yang lebih rendah, sehingga dapat digunakan sebagai pupuk, maka harus dikomposkan terlebih dahulu.

Penelitian tentang pemberian $\mathrm{BO}$ pada tanah sawah intensifikasi ini telah dilakukan dengan pemberian kompos berasal dari 5 tonha $^{-1}$ $\mathrm{JP}$ dan berasal dari $\left(2,5\right.$ tonha $^{-1} \mathrm{~T}+2,5$ tonha $\left.^{-1} \mathrm{JP}\right)$ pada musim tanam (MT) pertama (I). Gusnidar et al (2008) melaporkan pemberian 2,5 ton $\mathrm{T}$ dapat menghemat pengunaan $50 \mathrm{~kg}$ Urea $(25 \%$ kebutuhan tanaman padi) dan menghemat penggunaan $75 \mathrm{~kg} \mathrm{KCl}$ serta dapat menghemat pupuk P. Dari hasil penelitian penggunaan kompos 2,5 tonha ${ }^{-1} \mathrm{~T}+2,5$ tonha $^{-1} \mathrm{JP}$ yang diiringi pemberian Urea $150 \mathrm{kgha}^{-1}$ diperoleh produksi 8,07 tonha $^{-1}$ Gabah Kering Panen (GKP) setara dengan 6,89 tonha ${ }^{-1}$ gabah kering giling (GKG). Efek sisa kompos JP dan JP yang dicampur dengan $\mathrm{T}$, apakah masih bisa mengurangi penggunaan pupuk buatan (PB) perlu dipelajari melalui penelitian lanjutan. Tujuannya menentukan pengaruh sisa dari kompos asal $\mathrm{T}$ dan JP, untuk mensubsitusi sebagian pupuk pabrik dalam meningkaktan hasil padi sawah yang dikelola intensif, untuk musim tanam ke II.

\section{BAHAN DAN METODA}

Penelitian berlangsung bulan Januari sampai Mei 2009, di lahan sawah intensifikasi di Jorong Pasar Laban Kecamatan 2x11 Enam Lingkung, propinsi Sumatera Barat, berbentuk Rancangan Acak Kelompok (RAK), terdiri atas 6 perlakuan dengan 3 kelompok. Data tanah diuji kriteria, data tanaman dianalisis ragam, selanjut data yang signifikan diuji dengan uji LSD taraf 0.05. Riset ini berupa ES MT I ditambah PB dengan dosis yang sama dengan MT sebelumnya. Perlakuan pada MT ke II disajikan pada Tabel 1, sedangkan PB yang diberikan dalam Tabel 2.

Tabel 1. Perlakuan musim tanam ke II adalah:

\begin{tabular}{|c|c|c|}
\hline \multicolumn{3}{|r|}{ Perlakuan } \\
\hline Kode & Efek sisa kompos & Pupuk buatan \\
\hline A & - & Rekomendasi/R (Urea $200 \mathrm{~kg}+100 \mathrm{~kg}$ SP-36+75 kg KCl)ha ${ }^{-1}$ \\
\hline B & - & 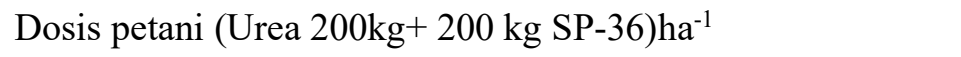 \\
\hline $\mathrm{C}$ & Jerami 5 ton ha $^{-1}$ & (Urea $200 \mathrm{~kg}+\mathrm{SP}-36100 \mathrm{~kg}+\mathrm{KCl} 75 \mathrm{~kg}$ ) $\mathrm{ha}^{-1}$ \\
\hline $\mathrm{D}$ & Jerami 5 ton ha- ${ }^{-1}$ & (Urea200 kg+ P-s 10 kg SP-36)ha ${ }^{-1}$ \\
\hline $\mathrm{E}$ & $\mathrm{T} 2,5$ ton/ha+ $\mathrm{J} 2,5$ ton $\mathrm{ha}^{-1}$ & Urea $0.75 \mathrm{R}(150 \mathrm{~kg}+$ dan P-s. $10 \mathrm{kgSP}-36) \mathrm{ha}^{-1}$ \\
\hline $\mathrm{F}$ & $\mathrm{T} 2,5$ ton/ha+ $\mathrm{J} 2,5$ ton $\mathrm{ha}^{-1}$ & Urea $0.50 \mathrm{R}\left(100 \mathrm{~kg}+\mathrm{P}-\mathrm{s} .10 \mathrm{kgSP}-36 \mathrm{ha}^{-1}\right.$ \\
\hline
\end{tabular}


Tabel 2. Dosis pupuk buatan yang diberikan dalam penelitian.

\begin{tabular}{|c|c|c|c|c|c|c|}
\hline \multirow{3}{*}{ Perlakuan } & \multicolumn{6}{|c|}{ Pupuk Buatan } \\
\hline & \multicolumn{2}{|c|}{ Dosis 1 ha } & & & \multicolumn{2}{|c|}{ Dosis perpetak } \\
\hline & Urea & SP-36 & $\mathrm{KCl}$ & Urea & SP-36 & $\mathrm{KCl}$ \\
\hline & & \multicolumn{2}{|c|}{$\ldots \mathrm{kg} \mathrm{ha}^{-1} \ldots$} & \multicolumn{3}{|c|}{...g petak ${ }^{-1}$. } \\
\hline A & 200 & 200 & - & 360 & 360 & - \\
\hline B & 200 & 100 & 75 & 360 & 180 & 135 \\
\hline $\mathrm{C}$ & 200 & 100 & 75 & 360 & 180 & 135 \\
\hline $\mathrm{D}$ & 200 & 10 & - & 360 & 18 & - \\
\hline E & 150 & 10 & - & 270 & 18 & - \\
\hline $\mathrm{F}$ & 100 & 10 & - & 180 & 18 & - \\
\hline
\end{tabular}

Setelah percobaan MT I panen, tiap petakan sawah dibersihkan dari sisa-sisa JP, kemudian tanah sawah tersebut digenangi selama 2 hari, sehingga tanah jenuh air dan mudah untuk diolah. Pengolahan tanah MT ke II, dilakukan dengan menggunakan cangkul. Setelah selesai pengolahan tanah, diambil sampel tanah sebanyak 100 g secara komposit pada tiap-tiap petakan untuk dianalisis sifat dan ciri kimia tanahnya.

Persiapan persemaian dilakukan 15 hari sebelum tanam. Pengolahan tanah untuk persemaian sama dengan pengolahan tanah untuk percobaan, tetapi dibuat lebih awal. Penanaman dilakukan saat bibit berumur 12 hari. Penanaman bibit satu bibit perlubang tanam dengan jarak tanam $30 \mathrm{~cm} \times 30 \mathrm{~cm}$. Pemberian P-starter (P-s) berupa SP-36 sebanyak 18 g petak $^{-1}$ (setara $10 \mathrm{~kg} \mathrm{SP-36ha-1)}$ untuk perlakuan $\mathrm{D}, \mathrm{E}$ dan $\mathrm{F}$ dan pemberian pupuk $\mathrm{P}$ untuk perlakuan $\mathrm{A}, \mathrm{B}$ dan $\mathrm{C}$ diberikan pada saat tanam. Pupuk Urea diberikan 2 tahap yaitu tahap pertama diberikan 2 minggu setelah tanam (2 MST) dengan $1 / 3$ dosis Urea dan tahap kedua diberikan $2 / 3$ bagian lagi pada umur $6 \mathrm{MST}$, sedangkan untuk $\mathrm{KCl}$ diberikan seluruhnya pada umur 2 minggu. Pemupukan ditabur di permukaan tanah, karena populasi tanaman yang rapat, kecuali pemberian P-s langsung ke perakaran tanaman.

Pemeliharaan meliputi pengaturan air, penyiangan dan pengendalian hama dan penyakit. Tanah cukup dalam kondisi macakmacak, dan ditinggikan permukaan air saat dilakukan pembersihan gulma. Penyiangan gulma dilakukan 3 MST dan penyiangan dilakukan kembali apabila ada gulma yang tumbuh. Tanaman digenangi setinggi $5 \mathrm{~cm}$ pada masa generatif sampai 2 minggu sebelum panen (2 MSP). Tindakan pengendalian hama dan penyakit dilakukan dengan menyemprot tananam dengan Ripcord 5 EC (1 cc/liter) saat ada serangan hama, yaitu pada umur 8 MST.

Panen dilakukan pada umur 110 hari yang ditandai dengan telah menguningnya bulir lebih dari $90 \%$ dan biji telah keras bila ditekan dengan kuku. Tanaman dipanen dengan menggunakan sabit dengan cara memotongnya lebih kurang $2 \mathrm{~cm}$ dari permukaan tanah. Setelah itu bagian gabah dan jerami dipisahkan, kemudian ditimbang bobot basahnya, selanjutnya diambil sampel untuk pengamatan di laboratorium.

Pengamatan terhadap tanah adalah analisis beberapa ciri kimia tanah awal meliputi : N (Kjeldhal), C-org (Walkley dan Black), dan ratio $\mathrm{C} / \mathrm{N}, \mathrm{P}$ (Bray II), K-dd, Ca-dd), natrium ( $\left.\mathrm{Na}-{ }_{\mathrm{dd}}\right)$ dan $\mathrm{Mg}-$ dd dicuci dengan Amonium asetat pH $71 \mathrm{~N}$, Kemampuan tanah menukarkan ion positif diekstrak dengan NH4OAc, $1 \mathrm{~N} \mathrm{pH} \mathrm{7,} \mathrm{tembaga}(\mathrm{Cu})$ dan seng ( $\mathrm{Zn})$ metoda pencucian, silikat ( $\mathrm{Si}$ ) metoda Kolorimeter.

Pertumbuhan dan perkembangan tanaman diamati (tinggi,, anakan total, anakan produktif, bobot kering jerami (BKJ), bobot gabah kering (BKG), dan kualitas biji. 


\section{HASIL DAN PEMBAHASAN Sifat tanah sebelum tanam}

Ciri kimia tanah MT ke II (Tabel 3), kandungan $\mathrm{C}$-org pada semua perlakuan berada pada kriteria sangat tinggi. Kandungan $\mathrm{C}$-org tertinggi terdapat pada perlakuan $\mathrm{D}$, yaitu sebesar $8,42 \%$ dan terendah terdapat pada perlakuan A $(7,22 \%)$. Tingginya kandungan C-org pada semua perlakuan, disebabkan oleh kandungan $\mathrm{BO}$ dari tanah juga tinggi karena termasuk ordo Andisol.

Tabel 3. Hasil analisis sifat kimia tanah setelah tanam I di lahan sawah intensifikasi Sicincin kabupaten Padang Pariaman

\begin{tabular}{|c|c|c|c|c|c|c|c|c|c|c|c|c|}
\hline \multirow{2}{*}{ Analisis tanah } & \multicolumn{12}{|c|}{ Perlakuan } \\
\hline & (A) & & (B) & & (C) & & (D) & & (E) & & $(\mathrm{F})$ & \\
\hline C-Org (\%) & & st & & st & & st & & st & & st & & st \\
\hline & 7,22 & & 7,28 & & 8,12 & & 8,42 & & 7,32 & & 7,41 & \\
\hline N-tot (\%) & 089 & st & 088 & st & & st & & st & & st & 0,95 & st \\
\hline $\mathrm{C} / \mathrm{N}$ & 8,11 & $\mathrm{r}$ & 8,88 & $\mathrm{r}$ & 9,33 & $\mathrm{r}$ & 8,95 & $\mathrm{r}$ & 8,61 & $\mathrm{r}$ & 7,80 & $\mathrm{r}$ \\
\hline P-Bray 2 (ppm) & 200,21 & st & 196,29 & st & 200,04 & st & 190,56 & st & 229,72 & st & 196,54 & st \\
\hline $\operatorname{KTK}\left(\mathrm{cmol}(\mathrm{kg})^{-1}\right)$ & 42,18 & st & 42,37 & st & 38,61 & $\mathrm{t}$ & 42,39 & st & 47,92 & st & 43,19 & st \\
\hline $\mathrm{K}_{\text {-dd }}\left(\mathrm{cmol}(\mathrm{kg})^{-1}\right)$ & 1,59 & st & 1,52 & st & 1,89 & st & 1,66 & st & 1,75 & st & 1,69 & st \\
\hline $\mathrm{Na}-\mathrm{dd}\left(\mathrm{cmol}(\mathrm{kg})^{-1}\right)$ & 0,65 & $\mathrm{~s}$ & 0,63 & $\mathrm{~s}$ & 1,00 & $\mathrm{t}$ & 0,72 & $\mathrm{~s}$ & 0,79 & $\mathrm{t}$ & 0,85 & $\mathrm{t}$ \\
\hline $\left.\mathrm{Ca}-\mathrm{dd}\left(\mathrm{cmol}(\mathrm{kg})^{-1}\right)\right)$ & 0,15 & sr & 0,11 & $\mathrm{sr}$ & 0,12 & $\mathrm{sr}$ & 0,17 & $\mathrm{sr}$ & 0,23 & $\mathrm{sr}$ & 0,08 & $\mathrm{sr}$ \\
\hline $\mathrm{Mg}_{\text {-dd }}\left(\mathrm{cmol}(\mathrm{kg})^{-1}\right)$ & 0,58 & $\mathrm{r}$ & 0,46 & $\mathrm{r}$ & 0,35 & $\mathrm{sr}$ & 0,29 & $\mathrm{sr}$ & 0,35 & $\mathrm{sr}$ & 0,45 & $\mathrm{r}$ \\
\hline $\mathrm{Si}$ (ppm) & 31,98 & sk & 32,05 & sk & 32,49 & sk & 34,74 & sk & 32,66 & sk & 33,97 & sk \\
\hline Cu-tersedia (ppm) & 12,92 & $\mathrm{sr}$ & 15,64 & $\mathrm{r}$ & 15,82 & $\mathrm{r}$ & 17,36 & $\mathrm{r}$ & 14,69 & $\mathrm{sr}$ & 15,29 & $\mathrm{r}$ \\
\hline Zn-tersedia (ppm) & 46,86 & $\mathrm{r}$ & 47,48 & $\mathrm{r}$ & 22,75 & $\mathrm{r}$ & 31,39 & $\mathrm{r}$ & 30,47 & $\mathrm{r}$ & 46,43 & $\mathrm{r}$ \\
\hline pH di lapangan & 6,54 & am & 6,45 & $\mathrm{am}$ & 6,54 & am & 6,47 & am & 6,46 & am & 6,27 & am \\
\hline
\end{tabular}

Keterangan $: \mathrm{st}=$ sangat tinggi, $\mathrm{t}=$ tinggi, $\mathrm{s}=$ sedang, $\quad \mathrm{r}=$ rendah, $\mathrm{sr}=$ sangat rendah , $\mathrm{sk}=$ sangat kurang, am = agak masam

Nilai $\mathrm{N}_{\text {tot }}$ MT ke II terjadi peningkatan dari kriteria tinggi menjadi kriteria sangat tinggi. Keadaan ini di sebabkan dekomposisi BO telah melapuk sempurna sehingga unsur hara MT ke II lebih tersedia daripada MT I. Treatment A $(200 \mathrm{~kg}$ Urea/ha $+100 \mathrm{~kg}$ SP$36 / \mathrm{ha}+75 \mathrm{~kg} \mathrm{KCl} / \mathrm{ha}$ ) sebagai pembanding perlakuan-perlakuan lainnya. Selain itu juga dibandingkan dengan dosis pemupukan yang digunakan petani (B). Kandungan unsur hara terutama $\mathrm{N}$ - tot tanah beragam pada setiap perlakuan. Kadar nitrogen tanah terbesar
$0,95 \mathrm{~g} / 100 \mathrm{~g}$, terdapat pada sisa pemberian perlakuan $\mathrm{F}$ dan paling minimal efek treatmen A, yaitu $0,82 \%$. Efek sisa kompos yang diiringi dengan pemberian PB $75 \%$ Ru dan P-s (E) mampu meningkatkan $\mathrm{N}$ - tot tanah sebesar $0,03 \%$ dan $0,13 \%$ (F) bila dibandingkan dengan input rekomendasi (A). Efek sisa (kompos JP 5 tonha $^{-1}$ ) yang diiringi dengan PB rekomendasi (C) dan $100 \% \mathrm{Ru}+\mathrm{P}-\mathrm{s}$ (D) juga dapat meningkatkan kandungan $\mathrm{N}-$ tot tanah sebanyak $0,05 \%$ (C) dan $0,12 \%$ (D) dibandingkan dengan input rekomendasi (A). 
Menurut Suryadi (1992), limbah organik termineralisasi ke bentuk $\mathrm{N}$ tersedia, akibatnya kadar $\mathrm{N}$ bertambah dalam tanah.

Tingginya kandungan $\mathrm{N}_{\text {-to }}$ tanah dari sisa treatmen $\mathrm{F}$, dipengaruhi oleh penambahan bahan asal $\mathrm{T}+\mathrm{JP}$. Hijauan $\mathrm{T}$ yang digunakan MT sebelumnya mengandung $3,43 \% \mathrm{~N}$ dan $\mathrm{N}-$ tot J sebesar 0,79\% (Gusnidar et al, 2008). Yumna et al (2006) melaporkan bahwa setiap penambahan $\mathrm{T}$ untuk mensubtitusi 50\% NK PB dapat meningkatkan $\mathrm{N}_{\text {-tot }}$ tanah sebesar $0,2 \%$ pada lahan kering Ultisol..

Kandungan $\mathrm{N}$-tot tanah menentukan nilai $\mathrm{C}: \mathrm{N}$, yang perbandingannya di musim berikut dalam kriteria rendah. Ratio $\mathrm{C} / \mathrm{N}$ tanah tertinggi adalah 9.33 yang diperoleh pada perlakuan ES input $C$, dan yang terendah pada input $F$ sebesar 7.80. Selanjutnya, kandungan $\mathrm{P}_{\text {-ters }}$ tanah MT ke II masih dalam kriteria sangat tinggi. Nilai P- ters tertinggi diperoleh pada perlakuan sisa E, yaitu sebesar 229,72 ppm sedangkan yang terendah diperoleh pada perlakuan sisa $\mathrm{D}$, yaitu 190,56 ppm. Tingginya nilai $\mathrm{P}_{\text {-ters }}$ pada perlakuan sisa E disebabkan karena pada MT yang lalu telah diberikan kompos dari JP dan T yang mempunyai kadar $\mathrm{P}$ sebesar $0.335 \%$. Sedangkan pada perlakuan D rendah, karena kadar P dari kompos JP juga rendah yaitu sebesar $0.162 \%$. Hakim et al (1986) menyatakan bahwa faktor yang mempengaruhi ketersediaan $\mathrm{P}$ di dalam tanah reaksi tanah, kandungan BO, lamanya proses berlansung, suhu dan tipe mineral. Peningkatan ketersediaan $\mathrm{P}$ adalah akibat pemberian kompos, sehingga mampu merobah reaksi tanah.

Kandungan $\mathrm{P}$ yang tinggi, juga karena penambahan $\mathrm{P}$ berupa pupuk komersil yang sering dan terus pada satu periode tanam, dan telah berlansung lama ( $>50$ tahun). Setiap periode tanam tersebut, selalu menyisakan $\mathrm{P}$ dan terakumulasi di salam tanah. Kadar P yang tinggi pada sawah yang dikelola intensif, selain sisa pupuk $\mathrm{P}$ setiap kali tanam, juga karena kelarutan pupuk P komersil lambat dan bisa terfiksasi. Diharapkan kompos T dan JP bisa menambah larut residu di tanah SI. Harjowigeno dan Rayes (2001), Kyuma
(2004), menyatakan bahwa hara P di tanah sawah larut akibat adanya air tergenang. Semakin lama digenangi, kelarutan $\mathrm{P}$ tidak nyata walaupun ada efek kompos diawal pemberian.

Kemampuan tukass kation yang tertinggi terdapat pada perlakuan ES perlakuan E yaitu 47,92 me/100g. Tingginya KTK pada perlakuan $\mathrm{E}$ disebabkan pengaruh $\mathrm{BO}$ pada MT sebelumnya. Nilai KTK terendah $(38,61 \mathrm{me} / 100 \mathrm{~g})$ terdapat pada perlakuan ES (kompos dari JP 5 tonha $^{-1}$ ) $+\mathrm{R}(\mathrm{C})$. Hakim et al (1986) menyatakan bahwa yang mempengaruhi KTK tanah adalah: 1) reaksi tanah dan $\mathrm{pH}, 2$ ) tekstur tanah atau jumlah liat, 3) jenis mineral liat, 4) $\mathrm{BO}, 5)$ pengapuran dan pemupukan.

Untuk nilai $\mathrm{K}$-dd yang tertinggi pada MT ke II diperoleh pada ES (kompos dari JP 5 tonha $\left.^{-1}\right)+\mathrm{R}$ (C) sebanyak 1,86 me/100g, diikuti ES kompos perlakuan E, yaitu 1,75 me/100g. Dosis pemupukan yang biasa dilakukan petani atau B, dan dosiis rekomendasi umum, nilai $\mathrm{K}$-dd masing-masing sebesar 1,59 dan 1,52 me/100g. Efek sisa pemberian kompos JP dan kompos $(\mathrm{T}+\mathrm{JP})$ mampu menyediakan hara bagi tanaman berikutnya. Berdasarkan hal tersebut, maka kompos dapat mensuplai $\mathrm{K}$ utuk tanaman padi, baik di MT I maupun di MT II.

Meningkatnya ketersediaan $\mathrm{K}$ dan $\mathrm{Na}$ adalah akibat pemberian BO pada MT I, hal ini disebabkan oleh kadar $\mathrm{K}$ yang dikandung $\mathrm{BO}$ tersebut. Pada penelitian Gusnidar et al (2008) $\mathrm{T}$ mengandung $\mathrm{K}$ sebesar 4,16\%, sedangkan JP mengandung K sebanyak 1,93\%. Untuk JP yang dikomposkan selama 1 bulan mengandung $\mathrm{K}$ sebanyak 0,449 \%, serta JP dan $\mathrm{T}$ yang dicampur pengomposannya mengandung $\mathrm{K}$ sebesar 0,889 \%.

Kandungan Na-dd berada pada kriteria sedang sampai tinggi. Kadar $\mathrm{Na}$ terbanyak terdapat pada input $\mathrm{C}$ sebesar $1,0 \mathrm{me} / 100 \mathrm{~g}$ diikuti oleh perlakuan $F$ sebanyak 0.85 me/100g. Terjadinya peningkatan Na-dd pada MT ke II, dibanding hasil analisis sebelum tanam pada MT I. Keadaan ini dapat disebabkan oleh pengaruh ES BO. Sudah diketahui bahwa, dalam proses dekomposisi 
BO akan menghasilkan AO yang mampu melepaskan logam-logam yang terjerap, termasuk $\mathrm{Na}$ sehingga menjadi tersedia bagi tanaman.

Kandungan $\mathrm{Ca}$ juga bertambah dibandingkan data hasil analisis tanah sesudah inkubasi BO pada MT I, walaupun masih dalam kriteria yang sama (sr). Kadar $\mathrm{Ca}$ tanah yang paling banyak pada perlakuan $\mathrm{E}$ yaitu sebesar $0,23 \mathrm{me} / 100 \mathrm{~g}$ dan diikuti oleh perlakuan D sebesar 0,17 me/100 g. Tingginya kandungan $\mathrm{Ca}-\mathrm{dd}$ pada perlakuan $\mathrm{E}$, adalah akibat penambahan $\mathrm{BO}$ berupa $\mathrm{T}$ dan JP pada MT sebelumnya. Bahan organik tersebut mengandung $\mathrm{Ca}$ cukup tinggi, sehingga bisa menyumbangkan $\mathrm{Ca}$ di dalam tanah. Menurut Hakim dan Agustian (2003) bahwa tingginya kandungan $\mathrm{Ca}-\mathrm{dd}$ pada tanah yang diberi $\mathrm{T}$ disebabkan karena $\mathrm{T}$ mengandung $1,46 \% \mathrm{Ca}$. Ini berarti $\mathrm{T}$ tidak hanya sebagai sumber $\mathrm{N}$ dan $\mathrm{K}$, tetapi juga sumber Ca bagi tanaman.

Selanjutnya, nilai $\mathrm{Mg}$-dd menurun pada MT ke II, adalah akibat diserap oleh tanaman, dan hampir tidak pernah ditambahkan melalui pupuk, walaupun pada tahap awal tanam, $\mathrm{Mg}$ masih tinggi, ternyata MT ke II menjadi rendah. Dengan demikian unsur ini sudah seharusnya ditambahkan setiap MT.

Kandungan $\mathrm{Si}$ tanah MT ke II termasuk kriteria sangat kurang. Kurangnya kandungan Si tanah MT ke II juga telah diserap oleh tanaman pada MT I. Walaupun perlakuan dengan penambahan bahan kompos JP dan JP+T, Si juga tetap dalam kriteria sangat kurang. Berarti belum terpenuhi kebutuhan Si bagi tanaman. Unsur Si merupakan unsur penunjang utama yang dibutuhkan oleh tanaman padi. Rosmarkam dan Yuwono (2002) menyatakan bahwa $\mathrm{SiO}_{2}$ sangat penting untuk ketahanan tanaman. Jika ketersediaannya $<0.05$ maka tumbuhan mudah rebah, sehingga diperlukan senyaa ini agar tumbuhan kuat dan tidak mudah tumbang. Ketersediaan si dalam tanah juga menambah ketersediaan P, karena Si dapat melepaskan Pretensi. Akibatnya ketersediaan $\mathrm{p}$ bertambah. Berhubung JP mengandung $\mathrm{Si}$ yang tinggi, maka sudah seharusnya bahan ini dikembalikan ke lahan setiap musim tanam. Di samping jerami berfungsi sebagai $\mathrm{BO}$, juga akan memasok hara Si ke tanah dan tanaman.

Selanjutnya untuk unsur hara mikro $\mathrm{Cu}$ dan $\mathrm{Zn}$, nilai $\mathrm{Cu}$ tanah MT ke II masih pada kriteria sangat rendah sampai rendah. Sedangkan nilai $\mathrm{Zn}$ pada kriteria rendah. Nilai $\mathrm{Cu}$ terendah terdapat pada perlakuan input pemupukan menurut tradisi petani (B) yaitu sebesar 12,92 ppm. Rendahnya kadar $\mathrm{Cu}$ dalam tanah disebabkan karena yang ditambahkan adalah pupuk makro $\mathrm{N}$ dan $\mathrm{P}$ setiap MT dalam dosis tinggi sehingga unsur hara mikro semakin rendah dalam tanah. Oleh sebab itu, unsur mikro $\mathrm{Cu}$ sudah harus ditambahkan setiap musim ke lahan bersamaan dengan pemberian pupuk makro utama berupa Urea $(\mathrm{N}), \mathrm{TSP} / \mathrm{SP}-36 \quad(\mathrm{P})$ dan $\mathrm{KCl}(\mathrm{K})$. Sedangkan nilai $\mathrm{Zn}$ terendah terdapat pada perlakuan ES input $\mathrm{C}$ sebesar $22,75 \mathrm{ppm}$. Rendahnya kadar $\mathrm{Cu}$ dan $\mathrm{Zn}$ ini disebabkan tidak adanya penambahan pupuk mikro setiap musim tanam ke lahan sawah, sedangkan tanaman terus menyerapnya, sehingga akan terus berkurang. Selain itu kekurangan unsur $\mathrm{Cu}$ dan $\mathrm{Zn}$ juga disebabkan oleh penggenangan pada lahan sawah dan penggunaan $\mathrm{P}$ dalam dosis tinggi tiap MT. Pusat Penelitian Tanah dan Agroklimat (2004) menyatakan bahwa penggenangan tanah sawah terus menerus seperti yang terjadi di lahan sawah yang berdrainase buruk dapat mengakibatkan menurunnya ketersediaan $\mathrm{Zn}$ dan $\mathrm{Cu}$, namun sebaliknya ketersediaan besi fero $\left(\mathrm{Fe}^{+2}\right)$ meningkat.

Rendahnya kadar Zn juga disebabkan karena tingginya kadar $\mathrm{P}$ di dalam tanah. Kestersediaan $\mathrm{P}$ berbanding terbalik dengan Zn. Berdasarkan hasil penelitian Jamil (1993) meningkatnya taraf pemberian $\mathrm{P}$ sering menyebabkan meningkatnya gejala kekahatan $\mathrm{Zn}$ pada tanaman atau mengakibatkan rendahnya ketersediaan $\mathrm{Zn}$ pada media tumbuh tanaman. Apabila konsentrasi $\mathrm{Zn}$ rendah dan konsentrasi $\mathrm{P}$ tinggi atau sebaliknya maka akan terbentuk persenyawaan antara $\mathrm{Zn}$ dan $\mathrm{P}$ berupa senyawa $\mathrm{Zn}_{3}\left(\mathrm{PO}_{4}\right)_{2}$. $4 \mathrm{H}_{2} \mathrm{O}$ yang tidak larut.

\section{Tinggi tanaman, Jumlah anakan total}


Tinggi tanaman yang disajikan pada Tabel 4 tidak berbeda nyata, walaupun tinggi tanaman pada perlakuan ES kompos JP 5 ton/ha + Urea $200 \mathrm{~kg} / \mathrm{ha}+\mathrm{SP}-36100 \mathrm{~kg} / \mathrm{ha}+\mathrm{KCl} 75 \mathrm{~kg} / \mathrm{ha}(\mathrm{C})$ tumbuh lebih tinggi dari pada perlakuan lainnya $(87,39 \mathrm{~cm})$. Tinggi tanaman terendah $75,30 \mathrm{~cm}$ pada ES perlakuan F. Hal ini dapat disebabkan oleh kurang tersedianya hara lain seperti $\mathrm{Ca}$ dan unsur hara mikro $\mathrm{Cu}$ dan $\mathrm{Zn}$. Pada umumnya petani selalu menambahkan pupuk makro N, P dan K saja, sedangkan hara lain ikut terbawa waktu panen sehingga terjadi ketidakseimbangan hara dalam tanah. Ketidakseimbangan hara inilah yang menyebabkan tanaman padi tidak dapat tumbuh dan berproduksi dengan baik.

Tabel 4. Hasil pengamatan tanaman musim tanam II yang dipengaruhi sisa jerami dan titonia yang dikomposkan pada sawah intensifikasi Sicincin kabupaten Padang Pariaman

\begin{tabular}{lcccccc}
\hline Pengamatan tanaman & \multicolumn{7}{c}{ Perlakuan } \\
\cline { 2 - 7 } & $\mathrm{A}$ & $\mathrm{B}$ & $\mathrm{C}$ & $\mathrm{D}$ & $\mathrm{E}$ & $\mathrm{F}$ \\
\hline Tinggi tanaman (cm) & 80,39 & 86,03 & 87,39 & 76,83 & 77,94 & 75,30 \\
Jumlah anakan total (rumpun) & 26,75 & 32,03 & 33,11 & 27,42 & 28,89 & 27,42 \\
Jumlah malai (rumpun) & 21,31 & 22,14 & 22,53 & 20,30 & 22,97 & 22,19 \\
Bobot 1000 biji (g) & 18,97 & 19,10 & 19,17 & 19,03 & 18,93 & 19,43 \\
Bobot jerami (ton/ha) & 6,50 & 7,98 & 9,61 & 8,41 & 8,84 & 7,89 \\
Produksi GKG (ton/ha) & $5,54 \mathrm{c}$ & $6,62 \mathrm{~b}$ & $7,38 \mathrm{a}$ & $6,66 \mathrm{~b}$ & $5,46 \mathrm{c}$ & $5,35 \mathrm{c}$ \\
\hline
\end{tabular}

Angka-angka yang diikuti pada baris yang sama yang diikuti oleh huruf kecil yang sama berbeda tidak nyata menurut uji LSD pada taraf nyata 0.05 .

Pada Tabel 4, ES input $\mathrm{C}$ diperoleh anakan total tertinggi (33,11 rumpun), dan jumlah anakan terendah diperoleh pada input tradisi petani (B) yaitu sebesar 26,75 perrumpun. Jika dibandingkan antara ES C, dengan input tradisi petani (B), jumlah anakan total meningkat sebanyak 6,36 perrumpun. Tingginya anakan total pada perlakuan ES C, disebabkan karena masih adanya pengaruh pemberian kompos JP yang diberikan pada MT sebelumnya. De Datta (1981), dan Kyuma (2004) menerangkan bahwa pengelolaan lahan untuk budidaya padi harud diiringi dengan pengembalian $\mathrm{BO}$.

\section{Jumlah malai dan bobot 1000 biji}

Jumlah malai dan bobot 1000 biji cenderung sama antar perlakuan (20-22 buah), untuk malai (18-19 g), untuk bobot 1000 biji. Berarti ES kompos dari JP 5 ton/ha dan sisa input $\mathrm{T} 50 \%$ dan JP 50\% (jumlah tetap 5 ton/ha) masih mampu menyediakan hara tanah dan pengurangan penggunaan PB. Pengaruh lanjutan pada tanam kedua dari perlakuan $\mathrm{E}$, diperoleh jumlah malai lebih tinggi jika dibandingkan dengan input rekomendasi (A), berarti pengaruh sisa 5 ton/ha BO $(50 \% \mathrm{~T}$ dan $50 \% \mathrm{JP})$ diiring pemupukan Urea setara $150 \mathrm{~kg}$ setaip hekatar, $0 \mathrm{~kg} \mathrm{KCl} /$ ha dan pemupukan $\mathrm{P}$ cukup starter di awal tanam, dapat meningkatkan jumlah malai, namun pupuk Urea dapat dikurangi sebanyak $25 \% \mathrm{R}$, pupuk $\mathrm{KCl}$ tidak perlu diberikan (hemat $100 \mathrm{~kg}$ Urea/ha) dan pupuk $\mathrm{P}$ dapat dikurangi sebanyak $90 \mathrm{~kg}$ SP36/ha ( $90 \% \mathrm{R})$.

Hasil bobot 1000 biji tertinggi pada perlakuan ES input $\mathrm{F}$ sebanyak 19,43 g dan yang terendah diperoleh pada perlakuan ES perlakuan E, yaitu seberat 18,93 g. Dibandingkan deskripsi tanaman, bobot 1000 biji hasil penelitian MT ke II ini masih lebih rendah. Hal ini disebabkan ketidakseimbangan unsur hara dalam tanah sebagaimana yang telah dijelaskan sebelumnya.

\section{Bobot jerami dan bobot gabah}

Hasil tertinggi gabah MT ke II diperoleh pada perlakuan ES kompos jerami 5 ton/ha diiringi pemupukan Urea $200 \mathrm{~kg}$, SP$36100 \mathrm{~kg}$ dan $\mathrm{KCl} 75 \mathrm{~kg}$ untuk setiap 
hektarnya. (C) sebesar 7,38 ton GKG/ha, yang diikuti oleh perlakuan ES kompos jerami 5 ton dengan $200 \mathrm{~kg}$ Urea, dan pupuk $\mathrm{P}$ distarter setara $10 \mathrm{~kg}$ SP-36 untuk satu hektar (D) yaitu sebanyak 6,66 ton $\mathrm{GKG} /$ ha yang berbeda tidak nyata dengan perlakuan input rekomendasi 200 $\mathrm{kg} \mathrm{Urea} / \mathrm{ha}+100 \mathrm{~kg} \mathrm{SP}-36 / \mathrm{ha}+75 \mathrm{~kg} \mathrm{KCl} / \mathrm{ha}$ (A) yaitu sebesar 6,62 ton GKG/ha, sedangkan yang terendah diperoleh pada perlakuan ES kompos campuran $\mathrm{T}$ dan JP (50\%:50\%) sebanyak 5.0 ton dengan Urea setengah yang direkomendasikan, dan $\mathrm{P}$ yang distarterkan sebanyak $10 \mathrm{~kg}$ SP-36 tiap hektar (F) hanya diperoleh 5,35 ton GKG/ha.

Selanjutnya pada Tabel 4 , BKJ tidak berbeda nyata, dengan bobot jerami tertinggi didapat pada perlakuan ES kompos jerami 5 ton perhektar dengan Urea $200 \mathrm{~kg}, \mathrm{SP}-36100$ $\mathrm{kg}$ dan $\mathrm{KCl} 75 \mathrm{~kg}$ (C) yakni sebesar 9,61 ton/ha dan diikut oleh perlakuan ES kompos $T$ setara 2,5 ton dcampur $\mathrm{J} 2,5$ ton dan Urea $150 \mathrm{~kg}$, tidak diberi pupuk $\mathrm{KCl}$, dan $\mathrm{P}$ distarter, dengan hasil sebesar 8,84 ton/ha, sedangkan yang terendah pada perlakuan input pemupukan menurut tradisi petani sebesar 6,50 ton/ha.

Dibandingkan MT I BKJ akibat pengaruh ES BO lebih berat, namun tidak diikuti oleh peningkatan BKG. Dengan demikian dapat dikatakan bahwa unsur hara yang berasal dari sisa $\mathrm{BO}$ dengan $\mathrm{PB}$ yang diberikan tidak mencukupi untuk meningkatkan hasil padi. Walaupun demikian, pengaruh sisa dari kompos $\mathrm{J} 5$ ton/ha yang diberikan produksi sebesar 0,76 ton/ha (760 kg GKG) dengan diberi tambahan PB sesuai rekomendasi.

Apabila dianalisis secara ekonomi pengadaan serta pemberian kompos J pada MT I, masih memberi keuntungan kepada petani sebanyak $760 \mathrm{~kg} / \mathrm{ha}$ gabah di MT ke II. Di samping itu, kesuburan tanah dapat dipertahankan dengan jalan mengembalikan sisa panen ke lahan. Hal ini sesuai dengan pendapat Hardjowigeno (2003) yang menyatakan bahwa sisa panen harus dikembalikan ke tanah agar unsur hara yang hilang dari tanah tidak semakin besar.
Penggunaan kompos $\mathrm{J} 5$ ton/ha pada MT I yang diberi PB Urea $200 \mathrm{~kg}, 0 \mathrm{~kg} \mathrm{KCl}$, disertai $10 \mathrm{~kg}$ SP-36 setiap hektar yang diberikan secara starter, produksi masih lebih tinggi dari input PB rekomendasi (A). Walaupun hanya meningkat sebesar $40 \mathrm{~kg} / \mathrm{ha}$, namun pupuk $\mathrm{KCl}$ dapat dikurangi sebanyak $100 \% \mathrm{R}$ dan pupuk P dapat sebanyak $90 \mathrm{~kg}$ SP-36 setiap hektarnya. Pemupukan dengan dosis tradisi petani (B), maka perlakuan (D) produksinya lebih tinggi 1,12 ton/ha, dan berarti penghematan pupuk SP-36 sebanyak $190 \mathrm{~kg} / \mathrm{ha}$. Dari ketiga perlakuanpemupukan setara $200 \mathrm{~kg}$ Urea dan $100 \mathrm{~kg}$ SP-36, disertai $75 \mathrm{~kg} \mathrm{KCl}$ setiap hektarnya (A), ES pupuk organik dari J 5 ton/ha + Urea $200 \mathrm{~kg} / \mathrm{ha}+\mathrm{SP}-$ $36100 \mathrm{~kg} / \mathrm{ha}+\mathrm{KCl} 75 \mathrm{~kg} / \mathrm{ha}(\mathrm{C})$, dan ES pupuk organik dari $\mathrm{J} 5$ ton dan $200 \mathrm{~kg}$ Urea dengan P-starter setara $10 \mathrm{~kg} \mathrm{SP-36}$ perhektar (D) tersebut dan sesuai dengan tujuan penelitian ini, maka perlakuan $\mathrm{D}$ adalah perlakuan terbaik bila dilihat dari perolehan produksi dan pengurangan input PB yang diberikan.

Hal ini juga mengisyaratkan bahwa $\mathrm{J}$ sisa panen padi seharusnya dikembalikan ke lahan. Oleh sebab itu, sebaiknya J sehabis panen apabila belum dimulai pengolahan tanah sebaiknya dikomposkan di lahan dan tidak dibakar lagi dan dapat digunakan kapan dibutuhkan.

\section{KESIMPULAN}

Dari hasil penelitian yang telah dikemukan, maka ditarik kesimpulan sebagai berikut :

1. Sisa aplikasi kompos dari jerami 5 ton, diiringi pemberian Urea $200 \mathrm{~kg}$ dan SP36 cukup distarter saja sebanyak $10 \mathrm{~kg}$ perhektar merupakan hasil terbaik, dan dapat menghemat pupuk $\mathrm{KCl} 75 \mathrm{~kg}$, SP$3690 \mathrm{~kg}$ setiap hektarnya dan hasil gabah juga $>40 \mathrm{~kg}$ dari hasil padi dengan dosis pupuk menurut rekomendasi.

2. Sisa pemberian kompos dari jerami 5 ton, dipupuk dengan $200 \mathrm{~kg}$ Urea, 100 $\mathrm{kg} \mathrm{SP}-36$ dan $75 \mathrm{~kg} \mathrm{KCl}$, adalah input dengan GKG terbanyak yakni 7,38 ton 
perhektar. Residu pemberian kompos asal jerami mampu menambah produksi sebanyak $760 \mathrm{~kg}$ GKG perhektar

\section{DAFTAR PUSTAKA}

De Datta, S. K. 1981. Chemical change in submerged rice soil. In Principles and Practice of Rice Production. John Wiley and Sons. Halaman 89145.

Pusat Penelitian Tanah dan Agroklimat. 2004. Tanah Sawah dan Teknologi Pengelolaan. Bogor. Puslitbangtanak (Pusat Penelitian dan Pengembangan Tanah dan Agroklimat). 326 hal.

Gusnidar. 2007. Budidaya dan Pemanfaatan Tithonia diversifolia untuk Menghemat Pemupukan N, P, dan K Padi Sawah Intensifikasi [Disertasi]. Padang. Program Doktor Pascasarjana UNAND. 256 hal.

Gusnidar, S. Yasin dan Burbey. 2008. Pemanfaatan Gulma Tithonia diversifolia dan Jerami sebagai BahanOrganik In Situ untuk Mengurangi Pengguanaan Pupuk Buatan serta Meningkatkan Hasil Padi Sawah Intensifikasi. Padang. Universitas Andalas. 49 hal.

Hakim, N., M.Y Nyakpa, A.M. Lubis, G. Nugroho, M.R. Saul, M.A. Diha, G.B Hong, H.H. Bailey, 1986. Dasar-dasar Ilmu Tanah. Lampung. Penerbit Universitas Lampung. 488 hal.

Hakim, N., dan Agustian. 2003. Gulma Tithonia dan Pemanfaatannya sebagai Sumber Bahan Organik dan Unsur Hara Untuk tanaman Hortikultura. Laporan Penelitian Hibah Bersaing XI/I Perguruan Tinggi Fakultas Pertanian Universitas Andalas Padang.
Hardjowigeno, S. 2003. Ilmu Tanah. Jakarta. Akademika Pressindo. 286 hal.

Hadrjowigeno, dan M.L. Rayes. 2001. Tanah Sawah. Bogor. IPB. 154 hal.

Jamil. 1993. Pemupukan Tanaman Padi (Oryza sativa $\mathrm{L}$ ) dengan Mikromel Zn dan TSP Pada Tanah Sawah Kaya P. [Skripsi]. Padang. Fakultas Pertanian Universitas Andalas. 105 hal

Kyuma, K. 2004. Paddy Soil Science. Kyoto University ans Trans Pacific Press. Orinted in Melboure by BPA Print Group. 380p.

Liptan. 2000. Pengenalan dan Penggunaan Pupuk Alternatif. https://www.softwarelabs.com (30 juni 2008).

Naim, T. 1982. Pengaruh Pemberian Silikon pada Tiga Kelengasan Tanah terhadap Pertumbuhan dan Produksi Padi (Oryza sativa. L). [Tesis] Megister. Fakultas Pascasarjana. Bogor. IPB. 101 hal.

Pusat Penelitian dan Pengembangan Tanah dan Agroklimat. 2004. Sumber Daya Lahan Indonesia dan Pengelolaannya. Badan Penelitian dan Pengembangan Pertanian Departemen Pertanian. 242 hal.

Rosmarkam, A., dan N.W. Yuwono. 2002. Ilmu Kesuburan Tanah. Yogyakarta. Kanisius. 224 hal.

Suryadi. 1992. Pengaruh Pemberian Kompos dan Pupuk TSP terhadap Ketersediaan Fosfat dan Produksi Padi Sawah [Skripsi]. Padang. Fakultas Pertanian universitas Andalas. 
Yumna, F., N. Hakim dan Gusnidar. 2006. Efek Sisa Tithonia diversifolia Terhadap Sifat Kimia Ultisol dan Hasil Tanaman
Cabai Pada Musim Tanam Ke Dua. Fakultas Pertanian Universitas Andalas. Padang. 72 hal. 